\title{
Aksiologi \\ dalam Perspektif Islam
}

\section{Zainuddin}

Dosen tetap dan Kepala Unit Penerbitan STAIN Malang
I

Slam adalah agama Allah SWT yang berisikan ajaran-ajaran dan tuntunan yang harus dipegangi $C$ dan dipedomani oleh pemeluknya untuk kebahagiaan dunia maupun di akhirat. Ajaran-ajaran Islam tersebut meliputi ajaran tauhid dan syari'ah atau iman dan amal. Sudah barang tentu aspek-aspek ajaran Islam tersebut harus dipahami dan dimengerti melalui belajar atau pencarian ilmu. Di sinilah ilmu itu perlu dan penting. Dengan demikian ilmu merupakan bagian dari agama itu sendiri, ia menempati posisi atau kedudukan sebagai bagian dari agama dan meniliki fungsi sebagai instrumen/sarana untuk memperoleh tujuan agama, yaitu memperoleh kebahagiaan dunia maupun akhirat.

Karena ilmu sebagai bagian dari agama, maka mencarinya menjadi wajib hukumnya. Sehingga menjadi mafbum jika Rasul SAW pun menekankan pentingnya belajar dan mencari ilmu itu dalam tingkat "fardhu 'ain".

Ungkapan Al-ilmu Nurun, bahwa ilmu itu laksana cahaya adalah sangat tepat, karena memang ilmu itu memberikan petunjuk atau jalan kepada suatu perbuatan. Tanpa ilmu orang tak akan mampu melaksanakan tugas yang diembannya. Salah satu dari yang membedakan manusia dengan binatang adalah dari segi "keilmuan". ini. Binatang tak akan memiliki 
ilmu karena ia hanya memiliki instink. Oleh sebab itu manusia yang tak berilmu dan tak mau mencari ilmu ia tak lebih dari binatang karena kebodohannya. Bahkan instink binatang lebih tajam.

Kedudukan ilmu yang mulia dan tinggi itu seperti yang diungkapkan dalam beberapa ayat al-Qur'an, misalnya:

"...Allah meninggikan orang-orang yang beriman di antara kamu dan orang-orang yang diberinya ilmu pengetabuan beberapa derajat. Dan Allab Naba Mengetabui apa yang kamu kerjakan" ( Al-Mujadilah: 11).

"... Dan orang-orang yang mendalam iimunya itu berkata: Kami beriman kepada ajat-ayat yang mutasyabihat, semuanya itu dari sisi Tuhan kami'. Dan tidak dapat mengambil pelajaran dari padanya melainkan orang-orang yang berakal'". (QS. Ali Imran 7) lihat juga QS. An-Nisa'.

Dan Nabi bersabda:

"Sedikit ilmu lebih baik ketimbang banyak beribadab (tetapi tak berdasarkan ilmu)" (H.R. Turmizi, Nasai, Baihaqi dan Thabrani).

"Sesunggubnya perumpamaan ulama di muka bumi ini adalah ibarat bintang-bintang yang menerangi darat dan laut di dalam kegelapan. Jik a bintang-bintang itu mengbilang, maka gelaplah darat dan laut tersebut" (H.R. Abmad).

"Seutama-utamanya shadagah adalab seseorang yang belajar ilmu, kemudian mengajarkannya kepada saudara muslimnya" (H.R. Ibn Majah dan Abu Hurairah).

'Tika anak Adam meninggal dunia, maka putuslah amalnya kecuali tiga hal: shadagah jariyah, ilmu yang bermanfaat dan anak shalih yang mendoakan orang tuanya" (H.R. Muslim).

Keunggulan derajat atau nilai ilmu itu nampak dalam pemakaian sifat yang digunakan berulang kali (kurang lebih 160 kali), misalnya dalam surat $A$-Hujarat: 16, An-Naml: 6, Al-Insan: 30 dan seterusnya. Demikian pula penghargaan Islam terhadap ilmu itu nampak dalam pengangkatan ulamA' dan Malaikat di dalam melihat atau menyaksikan keesaan Tuhan (lihat QS. Ali Imran: 18). (Abdurrazak Naufal, tt: 160-161, Abdul Halim Mahmud, 1979: 62-63).

Diriwayatkan, bahwa ulama' itu memiliki kedudukan sederajat dengan para nabi karena ulama' itu mewarisi ilmunya dan menjelaskannya kepada umat serta memeliharanya dari penyimpangan orang yang bodoh.(Al-Aini, II, H. 3).

Karena kedudukan ilmu dalam Islam adalah sebagai bagian dari Islam, maka ia memiliki fungsi sebagai petunjuk kepada jalan yang benar, pembebas kebodohan dan taklid buta, alat untuk mencapai kemuliaan dan sebagai jalan 
untuk mendekatkan diri dan mengenal kepada Tuhan.

Ibn 'Arabi misalnya (sebagaimana yang dikutip W..C. .Chitick, 1989:150) mengatakan, bahwa ilmu itu berguna untuk mendekatkan diri kepada Allah SWT, sebagaimana firman-Nya :

\section{- "Dan Aku tidak menciptaakan jin dan} manusia melainkan untuk menyembah padaKı'(QS. Az-Zariyat:56)

Dalam mengartikan "untuk menyembah kepada-Ku" ini Ibn Abbas sebagaimana dikutip Chitick, Ibn Arabi mengartikan sebagai "untuk mengenalKu” (lihat pula Ibn 'Arabi, 11: 93,19).

Islam menghendaki kebenaran sebagaimana Allah adalah Zat yang benar (al-Hag). Demikian ilmu dalam Islam harus benar karena memenuhi tuntunan Tuhan yang maha benar tersebut. Oleh sebab itu, agar ilmu menjadi benar, maka ilmu itu harus diderivasi dari wahyu (alQur'an maupun al-Hadits). Ini suatu keharusan dan tidak boleh tidak. Karena untuk mendekatkan diri dan mengenal Tuhan diperlukan ilmu yang benar. Oleh sebab itu Tuhan mengecam kebodohan, taklid nenek moyang, sebagaimna termaktub dalam al-Qur'an :

"Dan apabila dikatakan kepada mereka 'marilah mengikuti apa yang diturunkan ole Allah dan mengikuti rosul
' mereka menjawab:'cukuplah bagi kami apa yang kami dapati dari bapak-bapak kami mengerjakannya'. Dan apakah mereka juga akari mengikuti nenek moyang mereka walaupun nenek moyang mereka tidak mengetahui apa-apa dan tidak (pula) mendapat petunjuk?’(QS. Al-Maidah: 104).

"Mereka menjawab: 'buikan karena itu) sebenarnya kami mendapati nenek moyang kami berbuat demikian"(QS. As-Syu'ara: 74). Dan lihat pula QS. Lukman : 21 dan al- Ahzab: 67).

Ilmu yang benar juga merupakan petunjuk keimanan sebagaimana firman Allah :

“Dan orang-orang yang telah diberi illmu menyakini, bahwasanya al-Qur'an itulah haq dari Tuhanmu lalu mereka beriman dan tunduk hati mereka kepadanya dan sesungguhnya Allah adalah pemberi petunjuk bagi orang-orang yang beriman kepada jalan yang lurus"(QS.al-Haj.34).

Ilmu juga merupakan petunjuk bagi manusia untuk mengelola dan menguasai alam jagad raya ini. Bagaimana manusia mendayagunakan sumber potensi bumi, laut maupun udara. Beberapa kemajuan teknologi dan industri yang nampak di hadapan kita ini -apalagi dalam era ultra modern nanti-adalah tak mungkin terjadi 
melainkan adanya ilmu yanng dimiliki oleh anak manusia tersebut.

Sebagai manusia yang berperan sebagai kballifab fil ardh, ia diserahi tugas dan tanggung jawab yang tidak ringan oleh Allah SWT dimuka bumi ini. Oleh sebab itulah manusia diberi penghormatan dan kedudukan yang lebih dibanding makhluk yang lain, malikat sekalipun. Konsekuensinya, mañusia harus mengemban amanah itu untuk di pertannggungjawabkan di sisi-Nya.

Dengan ilmu manusia seharusnya bisa mengenal dan mendekatkan diri kepada Allah SWT, karena tanda-tanda kekuasaan-Nya begitu jelas di hadapan manusia dan nyata di alam ini.

Firman Allah menegaskan :

"Sesunggubnya dalam penciptaan langit dan bumi, silib bergantinya malam dan siang. Babtera yang berlayar di laut membawa apa yang berguna bagi manusia, dan apa yang Allab turunkan dari langit berupa air, lalu dengan air itu Dia bidupkan bumi sesudab mati (kering) nya. Dan disebarkan di bumi itu segala jenis bewan dan pengisaran air dan awan yang dikendallian antara langit dan bumi, sunggub (terdapat) tanda-tanda (kekuasaan dan kebesaran Allab) bagi kaum yang memikirkan". ( QS. Al-Baqarab :164)

"Sesunggubnya dalam penciptaan langit dan bumi dan silib bergantinya malam dan siang terdapat tanda-tainda bagi orang-oraing yang berakal (yaitu) orang-orang yang mengingat Allab sambil berdiri atau duduk atau dalam keadaan berbaring, dan mereka memikirkan tentang penciptaan langit dan bumi. (seraya berkata: 'Ya Tuban kami, tiadalab Engkau menciptakan ini dengan sia-sia. Maba Suci Engkau, maka pelibaralab kami dari siksa neraka" (QS. Ali Imran: 190-191). Dan lihat al-A'raf : 19;85 dan Ar-Rum : 25.

Ilmu pengetahuan tidak lain adalah usaha manusia untuk memahami hukum Allah yang pasti bagi alam semesta ciptaan-Nya. Oleh karena itu ia memiliki nilai kebenaran, selama ia secara tepat mewakili hukum kepastian Allah (takdirNya). Maka dengan demikian, ilmu pengetahuan yang benar dengan sendirinya bermanfaat untuk manusia (Nurcholish Madjid,1990:6, lihat pula C. A.Qodir,1989:16).

\section{Aksiologi Islam}

Untuk membahas masalah ini, maka kita harus memulai dengan pertanyaan. Apa tujuan ilmu itu, untuk apa ilmu itu. Pertannyaan-pertanyaan tersebut menyangkut soal aksiologis atau nilai.

Telah terjadi perdebatan panjang dikalangan para ahli tentang tujuan ilmu tersebut. Istilah "ilmu untuk ilmu" dan 
"seni untuk sèni" merupakan pernyataan para ahli yang berpendapat, bahwa ilmu merupkan tujuan pokok bagi orang yang menekuninya. Sebagian berpendapat, bahwa tujuan ilmu adalah sebagai jalan atua sarana untuk memperoleh kemudahan-kemudahan dalam hidupnya di dunia.

Pengadilan inquisi Galilei Galileo pada tahun 1633 oleh gereja, karena pendapatnya bertolak belakang dengan agama, telah mempengaruhi proses perkembangan berpikir yang pada dasarnya mencerminkan antara ilmu yang ingin terbebas dari nilai-nilai di luar bidang keilmuan dan ajaran-ajarannya. Dalam kurun ini para ilmuwan berjuang menegakkan ilmu yang berdasarkan penafsiran alam sebagaimana adanya dengan semboyan "ilmu yang bebas nilai". Setelah pertarungan kurang lebih 250 tahun, maka para ilmuwan mendapat kemenangan (Jujun, 1990: 233).

Jadi, terdapat dua kelompok dalam merespon masalah moral dalam menghadapi dampak ilmu dan teknologi tersebut. Kelompok pertama menginginkan bahwa ilmu harus bersifat netral terhadap nilai-nilai baik itu secara ontologis maupun aksiologis. Dalam hal ini tugas ilmuwan adalah menemukan pengetahuan dan terserah pada orang lain untu mempergunakannya, apakanh ilmu tersebut digunakan untuk tujuan baik atau untuk tujuan buruk. Kelompok kedua berpendapat sebaliknya, bahwa netralitas ilmu terhadap nilai-nilai hanyalah terbatas pada metafisika keilmuan, sedangkan dalam penggunaannya dan pemilihan objek penelitian harus dilandaskan pada asas-asas moral (Jujun, 1990:235).

Telah dijelaskan di depan bahwa pada zaman pertengahan ilmu dikembangkan dan diorientasikan pada kepentingan agama (Kristen) dan baru memperoleh kemandiriannya semenjak adanya gerakan renaissance abad 15 dan aufklarung abad 18. Sejak saat itulah filsafat barat menjadi sangat antroposentris. Manusia merasa bebas, tidak terikat pada agama, tradisi, sistem sosial dan otoritas politik.

Dan di sinilah yang menyebabkan timbulnya "sekularisasi" (dalam artian filosofis) di barat. Para ilmuwan tidak lagi percaya dengan agama yang dianggap "membelenggu" kemajuan ilmu pengetahuan. Kepercayaan agama luntur karena agama dianggap tidak mendukung pertumbuhan ilmu dan cara berpikir yang ilmiah. Inilah benih sejarah timbulnya sekularisasi di Barat. Agama dianggap sebagai persoalan pribadi dan bahkan mereka antipati.

Bukan salah mereka jika mereka harus bersikap demikian, sebab agama 
tidak memiliki konsep yang benar tentang ilmu pengetahuan, atau setidaknya pemuka agama mereka tidak memiliki konsep tentang ilmu pengetahuan tersebut.

Bagaimana dengan Islam? Dalam pemikiran Islam, ilmu itu memiliki peran instrumen atau sarana untuk mencapai tujuan Islam itu sendiri, yaitu kebahagiaan di dunia atau akhirat. Dimana dalam kehidupan di dunia manusia harus senantiasa mengabdikan diri kepada Allah sebagai hamba-Nya untuk memperoleh ridha dan kebahagiaan kelak. Oleh sebab itu ilmu harus memiliki tujuan ke sana (ibadah).

Abdurrazak Naufal (tt.:57) memandang, bahwa tujuan ilmu sama dengan tujuan agama, yaitu untuk kesejahteraan umat manusia. Karena ilmu memiliki perhatian besar terhadap pendidikan jiwa manusia dan pertumbuhannya, serta menghendaki kepribadian yang luhur. Dan bahwa orang yang mencari ilmu adalah sama dengan mencari hakekat (kebenaran).

Mengutip peryataan Aristoteles, Naufal (tt.:53) mengatakan, bahwa orang yang mencari hakekat adalah orang yang cinta kebenaran dan orang yang cinta kebenaran adalah orang yang benar dan orang yang benar adalah orang yang berani dan orang yang berani adalah orang yang memiliki muru'ab dan orang yang memiliki muru'ab adalah orang yang mulia dan orang yang mulia adalah orang yang belas kasih, cinta kebaikan, keadilan, menyuruh yang baik dan mencegah yang mungkar. Tidaklah agama memiliki tujuan seperti itu?

Seperti yang dijelaskan oleh AlMaududi (1967:37-38) dalam Islamic Way of Life, bahwa sistem normal Islam itu memiliki ciri-ciri yang komprehensif, yang berbeda dengan sistem moral lainnya.

Ciri-ciri lain tersebut antara lain sebagai berikut:

1. Keridhaan Allah merupa-kan tujuan hidup Muslim dan merupakan sumber standar moral yang tinggi serta menjadi jalan bagi evaluasi moral kemanusiaan. Sikap mencari ridha Allah memberikan sanksi moral untuk mencintai dan takut kepada-Nya, yang pada gilirannya mendorong manusia untuk mentaati hukum moral tanpa paksaan dari luar. Dengan dilandasi iman kepada Allah dan hari kiamat, manusia terdorong untuk mengikuti bimbingan moral secara sungguh-sungguh dan jujur, seraya berserah diri secara ikhlas kepada Allah;

2. Semua lingkup kehidupan manusia senantiasa ditegakkan di atas moral Islami sehingga moral tersebut berkuasa penuh atas semua urusan 
kehidupan manusia, sehingga hawa nafsu dan kepentingan pribadi tidak diberi kesempatan untuk menguasaid kehidupan manusia. Moral Islam mementingkan keseimbangan dalam semua aspek kehidupan: individual maupun sosial;

3. Islam menuntut manusia agar melaksanakan sistem kehidupan yang berdarkan atas norma-norma kebajikan dan jauh dari kejahatan. Islam memerintahkan perbuatan yang ma'ruf dan menjahui perbuatan yang munkar, bahkan manusia dituntut supaya menegakkan keadilan dan memberantas segala kejahatan (lihat QS. Al-Hajj: 41, AliImran: 104).

Dengan demikian sistem moral dalam Islam berpusat pada sikap mencari ridha Allah, mengendalikan nafsu negatif dan kemampuan berbuat kebajikan serta menjauhi perbuatan keji dan jahat.

Dalam pandangan Islam, kecenderungan kepada wawasan yang kudus merupakan suatu keharusan, yaitu bahwa Allah adalah Zat Yang Maha Wujud, Yang Maha Mengetahui dan segala sumber dari ilmu pengetahuan. Ini sangat berbeda dengan konsep barat yang sekuler dan antroposentris. Karena sumber pengetahuan dalam Islam adalah kesadaran yang Kudus, maka tujuan ilmu pengetahuan, dalam Islam adalah kesadaran Yang Kudus pula ( Hossien Nasr, 1970:22 dan lihat C.A Qadir, 1989:5).

Ilmu yang benar dalam Islam dianggap sebagai petunjuk keimanan, sebagaimana firman Allah:

'Dan agar orang-orang yang telab diberi ilmu menyakini babuva al-Qur'an itulab yang bak dari Tubanmu, lalu mereka beriman dan abti mereka tunduk" (QS. Al-Hajj: 54 dan lihat pula Al-Fathir. 28).

Demikianlah ilmu membuahkan iman dan iman membuahkan khusyu'dan tawadbu' kepada Allah, Tuhan semesta alam. Dalam ayat lain, ilmu dan iman disebut bergandengan sebagaimana firman-Nya:

"Dan orang-orang yang diberi ilmu pengetabuan dan keimanan berkata (kepada orang-orang kafir): 'Sesunggubnya kami telah berdiam diri (dalam kubur) menurut ketetapan Allah, sampai bar kebangkitan" (QS. ArRum: 56).

Jadi dalam Islam, sistem moral itulah yang akan menjadi kontrol atau kendali bagi perbuatan manusia. Ilmu tanpa kendali iman akan teknologi, agama dan masyarakat. Epistemologi Islam merupakan matriks bahwa semua elemenelemennya berada dalam satu orientasi yang didasarkan atas jiwa kemanusiaan. 
Sardar mendasarkan, bahwa Islam merupakan sistem totalitas, sebuah agama, sistem budaya dan juga peradaban (Bandingkan dengan Gibb). Dan sebagai sistem yang holistik, Islam menyentuh setiap aspek upaya kemanusiaan. Etik Islam dan sistem nilainya melalui semua aktivitas kemanusiaan. Dan disamping itu Islam juga memiliki perspektif definisi atas sains dan teknologi baik secara filosofis, sosiologis maupun metodologis.

Sebagaimana kata Ali Kattani (1984:67), bahwa manusia dituntut untuk menggunakan pengetahuannya tidak hanya untuk mengenal Tuhannya saja, tetapi juga untuk memberikan pelayanan kepada manusia sebaik mungkin. Pengetahuan tentang Tuhan tidak berdasarkan atas kepercayaan yang buta, tetapi atas dasar pengetahuan terhadap hukum-hukum-Nya yang universal. Oleh sebab itu alam harus dipelihara sebaik mungkin bagi kepentingan manusia.

Sebagaimana konsep Islam, bahwa iman adalah pembenaran dengan hati, pengakuan dengan lisan dan pelaksanaan dengan amal saleh. Orang yang berilmu (ulama') dituntut untuk mengamalkan ilmunya, karena amal adalah buah atau hasil. Amal di sini memiliki arti yang luas. Ada amal untuk dirinya sendiri, ada amal untuk orang lain. Amal untuk diri sendiri misalnya, segala ilmu yang dimiliki itu dipraktekkan dalam kehidupan seharihari, sedangkan amal untuk orang lain misalnya, segala ilmu yang dimiliki itu disampaikan kepada orang lain misalnya melalui pengajaran dan memberikan pendidikan kepada orang lain. Inilah yang disebut dengan berilmu amaliah. Islam sendiri mengecam orang yang menyembunyikan ilmunya, sikap eksklusif. Sabda Nabi:

"Barang siapa yang ditanya tentang ilmu kemudian meriyembunyikanya (tidak mau menjawab), maka kelak dihari kiamat orang itu dikekang dengan api neraka" (H.R. Tirmidzi).

Segala ilmu yang dipraktekkan harus memiliki landasan ilmiah, sebab perbuatan tanpa dilandasi ilmu hanya akan menjadikan naif dan riskan. Hal inilah yang menjadikan motif adanya keharusan menuntut ilmu, sehingga manusia (Muslim) tidak akan berbuat tanpa adanya ilmu.

Islam juga sangat mengecam orang yang "mengatakan sesuatu", mengerti akan ajaran-ajaran Islam, tetapi tidak melaksanakannya (lihat QS. As-Shaf. 3).

Karena itu, sebagaimana janji Allah dalam al-Qur'an (lihat QS. Al- Mujadilab: 11), bahwa jaminan jaminan keunggulan dan superioritas, termasuk kemenangan dan kesuksesan akan dikaruniakan Allah 
kepada mereka yang beriman dan berilmu. Beriman dalam arti mempunyai arti Ketuhanan dalam hidupnya dengan menjadikan perkenan Tuhan sebagai tujuan segala kegiatannya. Dan berilmu berarti mengerti ajaran secara benar dan memahami lingkungan hidup dimana ia akan berkiprah, sosial budaya dan fisik, seperti ilmu yang dikaruniakan Tuhan kepada Adam sebagai bekal mengemban kekhalifahan di bumi (QS. Al-Baqarab: 31). Iman harus menyatu dalam diri seseorang, sebab jika tidak justru. akan membuat celaka, lebih celaka daripada orang yang berilmu (Nurcholis, 1992: vii).

Konsep ilmu dalam perspektif Islam berbeda dengan pemahaman Barat, science. Pengertian ilmu dalam Islam lebih luas wilayah jelajahnya, yaitu segala ilmu yang membawa dampak nilai guna, baik pengetahuan empiris maupun nonempiris, wujud material maupun wujud spiritual (rohani) (Zaitun, 1984: 42).

Seperti kata Zaitun (1984:42), ilmu dalam perspektif Islam dicirikan dengan empat karakteristik: objektif, kerendahan hati, kemanfaatan, keajegan atau terus-menerus.

1. Objektif, artinya, bahwa ilmu tidak diarahkan kepada kemauan hawa nafsu, subjektivitas, bias, fanatisme, dan seterusnya. Dalam hal ini al-Qur'an banyak menyebut-nyebut peran hawa nafsu dalam menyesatkan manusia, misalnya dalam Q.S, Al-Kabfi : 18: 68:

"Dan bagaimana kamu dapat sabar atas segala sesuatu, yang kamu belum mempunyai pengetabuan yang cukup tentang hal itu?".

2. Kerendahan hati, maksudnya adalah menjauhkan dari sikap arogansi intelektual, karena bagaimanapun kemampuan intelektual manusia itu terbatas. Sebagaimana firman Allah:

"Dan di atas semua orang yang berilmu adalab Zat yang Maba Mengetabui" (Q.S. Yusuf: 76).

“... Dan kamu sekalian tidak diberikannya ilmu kecuali hanya sedikit saja" (Q.S. Al-Isra: 17: 85).

Perhatikan penegasan Einstein tentang hal ini:

"Sesungguhnya akal manusia meski sampai pada tingkat yang tertinggi, tetap lemah untuk mampu menjelajah alam makro ini. Ibarat anak kecil yang memasuki sebuah perpustakaan besar yang buku-bukunya bertumpukan sampai ke atap, yang di tulis dalam berbagai bahasa. Anak kecil tersebut tahu bahwa ada seorang yang menulis buku-buku itu, tetapi ia tidak tahu siapa yang menulis dan bagaimana cara menulisnya. Ia juga tidak paham dengan berbagai bahasa yang ditulisnya. Kemudian anak kecil itu 
memperhatikan bahwa ada cara tertentu untuk menyusun buku-buku itu dan ada cara yang tidak dipahaminya, tetapi ia tahu keadaannya. Inilah gambaran atau posisi akal manusia di hadapan Tuhan, meski akal tesebut mencapai taraf ketinggiannya" (Zaitun, 1984: 43, dikutip dari at-Taftazani, 1982:210).

3. Kemanfaatan, yaitu ilmu yang berguna baik dari aspek empiris maupun non-empiris dalam aspek aqidah dan akhlak. Islam menekankan adanya ilmu yang bermanfaat, baik bagi individu maupun masyarakat umum. Oleh sebab itu dalam doa Nabi dinyatakan:

'Ya Allab sesunggubnya saya berlináung kepada-Mu dari bati yang tidak kbussyu' dan dari serian yang tidak Kau dengar dan dari jiw a yang tidak pernab puas dan dari ilmu yang tidak bermanfaat".

Dan sabda Nabi:

"Perumpamaan ilmu yang tidak bermanfaat adalab ibarat harta benda yang tidak diinfakkan untuk kepentingan di jalan Allab" (H.R. Ahmad dan Darimi).

4. Keajekan, artinya ilmu itu harus dicari terus-menerus, di mana saja dan kapan saja tanpa mengenal batas dan waktu (open-ended activity).

Sebagaimana yang dirumuskan Sardar (1989: 44), bahwa epistemologi Islam memiliki 9 ciri dasar: 1. Berdasar kerangka pedoman yang mutlak; 2 . Bersifat aktif; 3. Objektivitas dipandang sebagai persoalan umum, bukan pribadi; 4. Sebagian bersifat deduktif; 5. Memadu pengetahuan dengan , llai-nilai Islam; 6 . Bersifat inklusif, terbuka; 7. Berusaha menyusun pengalaman subjektif dan mendorong pencarian akan pengalamanpengalaman tersebut untuk memperoleh komitmen-komitmen nilai; 8. Memadu konsep-konsep tingkat pengalaman subjektif sesuai dengar tingkatan lainnya (sama dengan perluasan dari proses jangkauan proses "kesadaran" yang dikenal) termasuk dalam bidang imajinasi kreatif dan pengalaman spiritual; 9 . Mengandung nilai.

Dalam kaitannỵ dengan masalah kedudukan dan fungsi ilmu ini, Asghar Ali menjelaskan, bahwa ilmu dan bikmab sebagai dua kata kunci yang disebut dalam al-Qur'an. (lihat Asghar Ali 1993:35). Oleh sebab itu menurutnya, ilmu dan bikmab tersebut harus dipahami secara tepat untuk menjembatani Islam dengan dunia llodern dengan menekankan pada penelitian bebas dan pengatahuan ilmiah untuk menjamin kemajuan manusia.

Menurut Asghar, penyerapan indera pertama kali diproses melalui akal, kemudian ditata melalui fikir dan dari keduanya kemudian menghasilkan ilmu, 
dan ilmu lewat penghayatan yang mendalam dan konsepsi intuitif, melahirkan bikmah. Dengan demikian lantas muncul suatu hubungan yang linier yaitu: agl-fikr-ilm-bikmah.

Di dalam hirarkhi pengetahuan ini, 'agl bisa dilihat tetap berada pada tingkatan yang paling rendah dan hikmah berada pada tingkatan yang paling tinggi. Alasannya jelas: 'aql merupakan instrumen untuk memperoleh pengetahuan, bukan tujuan akhir yang diinginkan. 'Aql hanya bisa menghasilkan abstraksi-abstraksi, seperti yang sering terjadi di bidang filsafat spekulatif. Ia sama sekali tidak bisa menghasilkan sesuatu yang lebih baik sekadar pola-pola pemikiran abstrak yang indah tanpa melayani kepentingan manusia secara luas dengan cara yang lebih bermakna. Dalam kasus akal yang destruktif, 'agl bisa menghadirkan dirinya menjadi kekuatankekuatan setan yang dahsyat dan bahkan dapat menghancurkan dunia. Pekembangan nuklir dan senjata-senjata termonuklir, dengan dukungan sains dan teknologi, sekarang bisa menghancurkan dunia kita berkali-kali. ' $I / m$ dalam terminologi al-Qur'an, berarti pengetahuan agama, pengetahuan ilmiah atau pengetahuan lainnya, sementara bikmah mengacu pada penerapan ilmu pengetahuan demi kebaikan manusia, dan bukan demi kemandegan, kemunduran ataupun kerusakan. Hiki:ıah menuntut agar teknologi nuklir digunakan untuk kemajuan umat manusia, bukan untuk merusak. Ilmu dan hikmah harus bersama-sama dalam mewujudkan tujuan rububiyyah, pencarian demi kesempurnaan manusia. Dipandang dari sudut ini, ajaran al-Qur'an mempunyai relevansi besar di abad sckarang. Kalau banyak vested interest yang berkuasa menyalahgunakan 'ilm (pengetahuan) dan mengabaikan hikmah (kebijaksanaan), tentu saja selamanya akan mengabaikan kemanusiaan (Ali, 1993: 42).

Dalam sistem Islam, iman sangat esensial. karena, ilmu tanpa iman ternyata bukan saja tidak produktif dan boros, tetapi juga menghancurkan dan membahayakan. Perkembangan psikologi tentang fungsi iman dalam kehidupan manusia relah memberikan banyak pandangan berharga bagi kita. Erich Fromm, seorang tokoh psikoanalisa terkenal menyatakan, "gagasan apapun hanya akan menjadi kuat jika di dasarkan pada struktur karakter pribadi seseorang. Tidak ada gagasan yang lebih berpotensi daripada acuan rasanya (ensistional matrix)".

Dengan demikian, iman merupakan suatu yang sangat sentral dalam sistem pemikiran apapun, kalau sistem pemikiran itu ingin menjadi sistem pemikiran yang bermakna. Tanpa iman ia akan tinggal 
sebagai pendapat yang kosong. Karenanya, penerimaan suatu gagasan juga harus di dasarkan pada acuan emosional seseorang, dan hal ini tidak mungkin dilakukan tanpa iman. al-Qur'an mempunyai wawasan ini untuk persoalan-persoalan manusia, karena itulah ia menjadikan iman sentral bagi ajarannya. Konsepnya tentang iman bil Gbayb (iman pada yang gaib) adalah sangat mengagumkan, asal saja ia dipahami dengan tepat dan tidak dibelokkan ke ekstrim yang lain. Ghayb menurut Asghar, menyatakan potensipotensi dari kemungkinan-kemungkinan untuk perbaikan manusia yang tersembunyi dari pandangan kita, dan hanya Tuhan yang, pencipta kemungkinan-kemungkinan ini, yang Alimusl Gbaybi (Maha Mengetahui segala yang ghaib). Jadi, iman pada kemungkinan-kemungkinan perbaikan adalah iman terhadap masa depan yang menjadi inspirasi umat manusia. Iman bil Gbaib merupakan iman terhadap kemungkinan-kemungkinan masa depan yang tak terkira banyaknya. Iman bahwa Tuhan melalui manusia sebagai wakil-Nya (dalam terminologi al-Qur'an, kḅalifab), merupakan pencipta kemungkinankemungkinan tersebut (Ali,1993: 43).

Hubungan ilmu dan agama (baca: Islam) adalah hubungan simbiotik, karena agama menyeru kepada pencarian ilmu dan memberikan posisi mulia bagi para ilmuwan(lihat Q.S. Al-Mujadilah: 11, AzZumar: 9). Agama menjadi pembimbing bagi ilmu agar terarah dan terkendali langkahnya. Karena agama merupakan alat, maka menurut Zaitun (1984: 66) ia menjadi salah satu jalan menuju keimanan (lihat Q.S. Al-Fathir. 28).

Pada dasarnya ilmu dan agama sama-sama berurusan dengan kenyataan (realitas). Hanya saja tingkat dan ruang lingkupnya yang berbeda, demikian kata Syah Idris (1988: 2). Oleh sebab itu menurutnya, tidak perlu muncul pertanyaan yang mempersoalkan kesesuaian antara keduanya. (ilmu dan agama).

Para filsuf muslim juga memberikan penegasan, bahwa antara agama dan Ellsafat atau ilmu pengetahuan tidaklah bertentangan. Al-Kindi misalnya menjelaskan, bahwa filsafat adalah pengetahuan tentang y'ang benar (babtsun an-al-Haq). Tujuan agama adalah menerangkan apa yang benar dan yang baik. Demikian halnya dengan filsafat. Agama di samping wahyu juga mempergunakan akal seperti halnya filsafat (lihat Harun Nasution, 1973:15). 


\section{DAFTAR PUSTAKA}

Abdúrrazak Naufl. tt. Bain ad-Din wal-Tlm, Cairo, Maktabah al-Wahbah.

Abdul Halim Mahmud. 1979. Massaif al-Islam Min al-Fanni wal-Tho wal-Falsafi, Cairo Da as-Sya'bi.

Al-'Aini, Ahmad. tt. Umdat al-Qari’ Syarb Shabih al-Bukhari, Jilid II, Dar al-Fikr.

Al-Maududi. 1967. Islamic Way of Life, Lahore, Islamic Publications, Ltd.

Ali Kattani, 1984, "Science and Technology in Islam, The Underlying Value System: dalam Sardar, The Toush of Midas.

Asghar Ali 1993:35. Islam dan pembebasan, Yogyakarta, LKiS

C. A.Qodir. 1989. Filsafat dan Ilmu Pengetabuan dalam Islam, Jakarta, Yayasan Obc Indonesia.

Hossien Nasr. 1970. Science and Civilization in Islam, The New American Library

Harun Nasution. 1973. Falsafat dan Mistisisme dalanz Islam. Jakarm, Bulan Bintang

Ibn 'Arabi. tt. Futzubat al-Makiyyah, jilid II Mesir Dar al-Kutub al-Arabiyyah Gramedia.

Jujun S. Suriasumanteri. 1990. Ilnus dalam Perspektif Merah, Sosial dans Politik, Jakait:

Nurcholish Madjid. 1990. Pändangan Dunia al-Qur'an dalam majalah Inovasi, Yogyakartê UMY.

Nurcholis Madjid. 1992. Islam: Doktrin dan Peradaban, Jakarta, yayasan Paramadina.

Sardar, Ziauddin. 1989. The Future Mustim Civilization, terj. Bandung, Mizan.

W..C. Chitick, 1989, Ibn 'Arabi's Metaphisics of Imagination: The Sufi Path of Knowyedge, New York State University Press.

Zaitun, Hasan Husain. 1984. Al-Ijtibad ad-Dini fit-Tadris al-Ubsm. Dirasab 'alagah Bain adDin wal-1lm, Dar al-Ma'arif. 